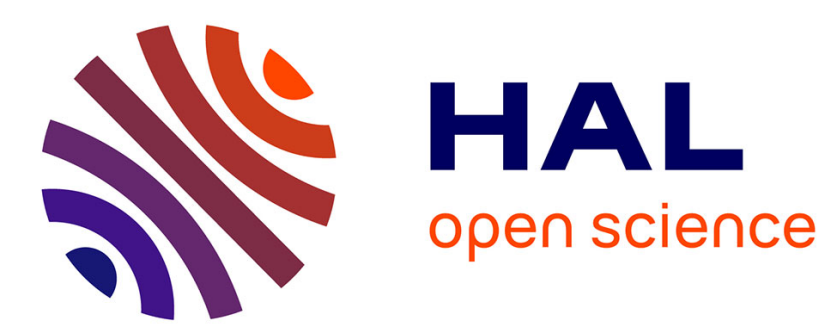

\title{
Bacteremia caused by multidrug-resistant bacteria in a French university hospital center: 3 years of collection
}

Romain Picot-Guéraud, Pierre Batailler, Yvan Caspar, Aurélie Hennebique, Marie-Reine Mallaret

\section{- To cite this version:}

Romain Picot-Guéraud, Pierre Batailler, Yvan Caspar, Aurélie Hennebique, Marie-Reine Mallaret. Bacteremia caused by multidrug-resistant bacteria in a French university hospital center: 3 years of collection. American Journal of Infection Control, 2015, 43 (9), pp.960-964. 10.1016/j.ajic.2015.05.004 . hal-03034268

\section{HAL Id: hal-03034268 \\ https://hal.science/hal-03034268}

Submitted on 22 Jan 2021

HAL is a multi-disciplinary open access archive for the deposit and dissemination of scientific research documents, whether they are published or not. The documents may come from teaching and research institutions in France or abroad, or from public or private research centers.
L'archive ouverte pluridisciplinaire HAL, est destinée au dépôt et à la diffusion de documents scientifiques de niveau recherche, publiés ou non, émanant des établissements d'enseignement et de recherche français ou étrangers, des laboratoires publics ou privés. 
Title: Bacteremia caused by multidrug-resistant bacteria in a French University Hospital Center: 3 years of collection

Picot-Guéraud Romain (1), Batailler Pierre, MD (1), Caspar Yvan, PharmD (2), Hennebique Aurélie (2), Mallaret Marie-Reine, MD (1) (3)

1: Unité d'Hygiène Hospitalière, Pôle Santé Publique, Centre Hospitalier Universitaire de Grenoble, FRANCE

2: Département des Agents Infectieux, Pôle de Biologie, Centre Hospitalier Universitaire de Grenoble, FRANCE

3: Université Grenoble-Alpes, ThEMAS TIMC-IMAG (UMR CNRS 5525)

Corresponding author: Romain Picot-Guéraud, Unité d'Hygiène Hospitalière, Pavillon E, CHU de Grenoble, Cs 10217 - 38043 GRENOBLE CEDEX 9

Tel number: +33672694814

Fax number: +33476765094

E-mail address: rpicotgueraud@ chu-grenoble.fr

Abbreviated title: Bacteremia caused by MDR bacteria

Word count: 2621 
Abstract

Objective: The aim of the study was to describe the characteristics of all bacteremias caused by multidrug-resistant bacteria in a university hospital center and to assess the mortality related to these events.

Design: Retrospective observational cohort study.

Setting: A 2200-bed acute and long-term care French university hospital center.

Patients: All patients with bacteremia caused by multidrug-resistant bacteria between 2011 and 2013 were included.

Methods: The characteristics of patients and bacteremias, antibiotic therapy within the first day, and 30-day mortality were collected from patients' medical records.

Results: A total of 228 patients were included with bacteremias caused by Enterobacteriaceae producing extended-spectrum- $\beta$-lactamase $(\mathrm{ESBL})(n=102)$, Enterobacteriaceae overproducing AmpC beta-lactamase ( $n=59)$, carbapenem-resistant Enterobacteriaceae $(n=3)$, ceftazidime- or carbapenem-resistant Acinetobacter baumannii ( $n=2)$, ceftazidime- or carbapenem-resistant Pseudomonas aeruginosa $(n=23)$, methicillin-resistant Staphylococcus aureus (MRSA) ( $n=40)$, and vancomycin-resistant Enterococcus (VRE) ( $n=2)$. The median Charlson comorbidity score was 6 . Inappropriate antibiotic therapy was prescribed in $41.7 \%$ of bacteremias and 30-day mortality was $23 \%$. For $20.9 \%$ of the patients who had had a positive bacteriological sample in the preceding 2 months, the initial antibiotic therapy was inappropriate. Four independent risk factors were statistically significant in multivariate analysis for 30-day mortality: multi-bacteria bacteremia (aOR=3.62; 95\%CI: $1.42-9.27)$, age $\geq 65$ years $(\mathrm{aOR}=6.08 ; 95 \% \mathrm{CI}: 2.17-17.04)$, liver disease (aOR: 6.56; 95\%CI: 2.15-19.97), and severe sepsis or septic shock (aOR=8.96; 95\%CI: 3.86-20.80). 
Conclusions: In this cohort of bacteremia patients, varied multidrug-resistant bacteria were found. A high rate of mortality and numerous patient comorbidities were also observed. More appropriate consideration of bacteriological antecedents could improve the pertinence of initial antibiotic therapy.

Keys words: bacteremia, blood-stream infection, multidrug resistance, mortality 
Introduction

Multidrug-resistant (MDR) bacteria incidence has been persistently increasing for many years ${ }^{1}$. In the meantime, the prevalence of bacteremia in France is also on the rise, which can be explained by the increase in risk factors and patients' comorbidities ${ }^{2}$. In 2012, bacteremias accounted for the fourth infectious site in the hospital patient population according to the national prevalence survey in France ${ }^{2}$. It was also shown that the bacteria isolated in bacteremia are more often MDR bacteria compared with other infectious sites ${ }^{2}$.

Several studies have demonstrated an increased fatal outcome in bacteremias caused by MDR bacterial infections such as $\mathrm{MRSA}^{3}$, resistant Pseudomonas aeruginosa ${ }^{4}$, ESBL producing bacteria $^{5,6}$, and $\operatorname{VRE}^{7}$ compared to drug-sensitive bacteria. This excess mortality seems to be caused by an association of host, bacteria, and treatment factors ${ }^{8}$.

The aim of the study was to describe the profile of patients and the characteristics of bacteremias due to MDR bacterial strains in a university hospital center. Identification of risk factors for mortality and for inappropriate antibiotic therapy in bacteremia involving MDR bacteria, all strains combined, were the secondary objectives. 
Materials and methods

Patient inclusion and characteristics

A retrospective observational cohort study was conducted between 1 January 2011 and 31

December 2013. All patients with bacteremia due to MDR bacteria in Grenoble University Hospital (2200 acute and long-term beds, France) were screened.

The MDR bacteria included were MRSA, VRE, ceftazidime- and/or carbapenem-resistant Acinetobacter baumannii, ceftazidime- and/or carbapenem-resistant $P$. aeruginosa, ESBL producing Enterobacteriaceae, AmpC overproducing Enterobacteriaceae, and carbapenemresistant Enterobacteriaceae.

The characteristics of each patient were collected from the medical records and the Charlson comorbidity score ${ }^{9}$ was calculated based on these data. The Simplified Acute Physiology Score $\mathrm{II}^{10}$ was collected in the summary of hospitalization of patients who stayed in the intensive care unit during the bacteremia episode. Most of characteristics collected are shown in Table 1.

Bacteriological methods

Bacterial strains isolated in the samples were identified using a VITEK2 ${ }^{\circledR}$ system (BioMérieux, Marcy l'Etoile, France). Antibiotic susceptibility was tested using the VITEK2 ${ }^{\circledR}$ system or the disk diffusion method. Minimal inhibitory concentration (MIC) breakpoints were based on the French guidelines in effect at the time of sampling ${ }^{11}$. Confirmation and 
phenotypic typing of the third-generation cephalosporin resistance mechanism were carried out using a specific disk diffusion method along with combination disk diffusion tests recommended by the national guidelines ${ }^{11}$. If a carbapenem-resistant strain was suspected with the VITEK2 ${ }^{\circledR}$ system, disk diffusion tests and exact MIC determination using Etest ${ }^{\circledR}$ strips (BioMérieux, Marcy l'Etoile, France) were performed for confirmation. If carbapenem resistance was confirmed, the strain was sent to the French national reference center for antibiotic resistance to confirm and precisely identify the resistance mechanism using the Carba NP Test and PCR (in-house techniques from the national reference center). Resistant strains of S. aureus (i.e., MRSA) identified by the VITEK $2^{\circledR}$ system were also confirmed using the disk diffusion method completed in case of discordance with immunochromatographic test targeting PBP2a protein (Alere ${ }^{\mathrm{TM}} \mathrm{PBP} 2 \mathrm{a}$ Culture colony test, Jouy-en-Josas, France). P. aeruginosa and A. baumannii resistance was investigated with the disk diffusion test and MIC determination using Etest ${ }^{\circledR}$ strips. Vancomycin-resistant Enterococcus strains were confirmed by identification of $v a n A / v a n B$ genes using a commercial PCR system (Xpert ${ }^{\circledR}$ vanA/vanB, Cepheid, Maurens-Scopont, France).

\section{Definitions}

Bacteremia was defined by at least one positive blood culture for one of the bacteria studied. Original source of the bacteremia was evaluated according to bacteriological samples at the presumed source and/or medical reports of clinical examination. In cases of discrepancy, the files were discussed with a second reviewer.

If the bacteremia occurred more than $48 \mathrm{~h}$ after hospital admission or if the patient was hospitalized in another hospital for more than $48 \mathrm{~h}$, it was considered nosocomial. Less than 
$48 \mathrm{~h}$ after hospital admission, the bacteremia was a healthcare-associated infection if it occurred during or after care. In other cases, bacteremia was considered community-acquired. Plausibility of the association was evaluated in each case as recommended ${ }^{12}$.

A recurrent bacteremia was defined by a new bacteremic episode during the study period. These must be preceded by a negative blood culture window after the first bacteremia and can be due to the same or another MDR bacterium.

Clinical state was mainly judged according to medical reports. In case of missing information on the patient's clinical condition, the following definitions were applied. Severe sepsis was defined by blood lactate $>4 \mathrm{mmol} / \mathrm{L}$, organ dysfunction, and/or hypotension $<90 / 40 \mathrm{mmHg}$ before fluid resuscitation. Definition of septic shock was persistent hypotension despite fluid resuscitation requiring vasopressive drugs ${ }^{13}$.

Colonization variable was defined as a positive bacteriological sample documented to the same bacterium as the one identified in bacteremia, in the previous 2 months without intercurrent negativity. This variable gather previous positive bacteriological samples with the same bacterium, related either to bacterial colonization or/and to an early antecedent of infection.

Information on the antibiotic therapy was collected on the day after the first positive blood culture. Appropriateness of antibiotic therapy was judged according to the results of susceptibility testing. Following current recommendations for clinical practice, the treatment of ESBL producing bacteria by piperacillin/tazobactam was considered inappropriate as piperacillin/tazobactam is not recommended for susceptible strains in case of severe infection. An active monotherapy by aminoglycoside was considered inappropriate for $P$. aeruginosa ${ }^{14}$. 
Patients and bacteremia characteristics according to the patient's condition were compared using the chi-square or Fisher exact test for qualitative variables and the Wilcoxon rank sum test for quantitative variables.

Risk factors of 30-day mortality and inappropriate antibiotic therapy were analyzed with a univariate logistic regression model on first bacteriemia episodes in the adult population. Because of missing data on their clinical state, some patients were excluded from the logistic regression model. Variables associated with a $p$-value $<0.20$ were selected for the multivariate logistic regression model. The logistic regression model was constructed by a backward selection approach based on the Wald statistic. Variables that did not significantly contribute to the model were removed. The interaction in the multivariate logistic regression model was analyzed according to the Wald statistic. Statistical significance was set at 0.05 (two-tailed) and data were analyzed with $\mathrm{R} \circledast$ software version $3.0 .2^{15}$. 
Results

Patient inclusion and characteristics

Two hundred forty-nine bacteremic episodes corresponding to 228 patients were detected from the database for the 3 years of the study. Twenty-one bacteremias were recurrent episodes in patients already included. The fate at 30 days was unknown for 6 patients. Patient characteristics are shown in Table 1 . These characteristics were those at the first bacteremic episode. The median age was 69 years (interquartile range [IQR]: 60-81) and the median Charlson comorbidity score was 6 (IQR: 4-8). More than half of the patients had neoplastic pathology $(53.1 \%)$. Almost $36 \%$ of the patients were immunodepressed at the bacteremia onset $(n=81)$. Forty-three percent of the patients $(n=98)$ had available bacteriological samples data from less than 2 months before the bacteremia onset, to guide toward a possible colonization with the same MDR bacterium. All patients combined, this variable was positive in $18.9 \%$ of the cases $(n=43)$. Fourteen percent of the patients $(n=36)$ were hospitalized in intensive care unit at the bacteremia onset or for take-in care. The median Simplified Acute Physiology Score II of the latter patients was 50 (IQR: 43-62).

Bacteremia characteristics

Most of bacteremia characteristics are shown in Table 2. Leading source of bacteremias were urinary tract infection $(28.1 \%)$ followed by intra-abdominal infection $(21.9 \%)$. Source of infection was unknown in 40 bacteremias (17.6\%). Most isolated MDR bacteria were ESBL 
producing Enterobacteriaceae (44.7\%), Enterobacteriaceae overproducing AmpC betalactamase (25.9\%), and MRSA (17.5\%). Glycopeptide-intermediate S. aureus was isolated in one case of bacteremia.

Combination of two MDR bacteria were found in three bacteremia cases (ESBL producing Enterobacter aerogenes and carbapenem-resistant $P$. aeruginosa; carbapenem-resistant $A$. baumannii and P. aeruginosa; ESBL producing Klebsiella pneumoniae and carbapenemaseproducing Enterobacter cloacae).

Clinically, $69.4 \%$ cases were simple sepsis and $30.6 \%$ were severe sepsis or septic shock. Five patients were excluded from the logistic regression models because of their unknown clinical status. A previous infection with the same MDR bacterium was known at the bacteremia onset in $11.0 \%$ of the cases.

For 33 bacteremias, a nonsurgical procedure such as endoscopy was known in the previous 30 days. Bacteremias were directly related to these nonsurgical procedures in $39.4 \%$ of the cases $(n=13)$. Among these, 8 were related to an intra-abdominal source, especially postendoscopic retrograde cholangiopancreatography, and 4 to a urinary tract source.

The median length of stay, except in the rehabilitation and long-term care units, was 23 days (IQR: 10-39), and the median time between hospital admission and bacteremia was 5 days (IQR: 1-18) all patients combined.

Recurrent bacteremia

Twenty-one cases of bacteremia were a second episode or more of patients already included during the study period. Eighteen of these were early recurrent bacteremia within 90 days after the previous bacteremic episode (85.7\%). Early recurrent bacteremia involved a total of 
15 different patients including one child. The same MDR bacterium was isolated in $83 \%$ of early recurrences $(n=15)$ relative to the initial bacteremia. The recurrences were excluded from the data analysis.

Antibiotic therapy

Antibiotic therapy at day 1 after positive blood sample was inappropriate in $41.7 \%$ of bacteremias. Multidrug therapy was prescribed in $51.3 \%$ of bacteremia cases $(n=117)$. No antibiotic therapy was prescribed in $4.4 \%$ of bacteremias within the $1^{\text {st }}$ day $(n=10)$. Of the 43 patients who had positive bacteriological samples to the same MDR bacterium in the 2 months preceding bacteremia (colonization or infection), $20.9 \%$ received inappropriate initial antibiotic therapy $(n=9)$. For patients who were suffering from a previously known active infection (i.e.: urinary tract infection, pulmonary infection, etc) by the same MDR bacterium, with available antibiotic susceptibility results at the bacteremia onset, appropriate antibiotic therapy rate was $92 \%(n=23)$.

Risk factor analysis of inappropriate antibiotic therapy at 1 day revealed two elements independently associated in this series: AmpC beta-lactamase overproduction ( $\mathrm{aOR}=2.36$; 95\%CI:1.22-4.59) and the presence of $P$. aeruginosa resistant to ceftazidime and/or carbapenem $(\mathrm{aOR}=3.15 ; 95 \% \mathrm{CI}: 1.16-8.55)$. On the opposite, another factor appeared statistically significant in multivariate analysis as a protective element: severe sepsis or septic shock $(\mathrm{aOR}=0.46 ; 95 \% \mathrm{CI}: 0.24-0.89)$. 
Fifty-one patients died within 30 days after bacteremia onset, for a 30-day mortality rate of $23 \%$. Four independent risk factors of 30-day mortality appeared statistically significant in multivariate analysis: bacteremia involving multiple bacterial strains $(\mathrm{aOR}=3.62 ; 95 \% \mathrm{CI}$ : 1.42-9.27), age $\geq 65$ years (aOR=6.08; 95\%CI: 2.17-17.04), liver disease (aOR: 6.56; 95\%CI: 2.15-19.97), and severe sepsis or septic shock (aOR=8.96; 95\%CI: 3.86-20.80) (Table 3). Among patients dead at 30 days, $33.3 \%$ died within the first 2 days after bacteremia onset $(n=17)$. However, half of them had received appropriate initial antibiotic treatment at 1 day $(n=8)$. In the Charlson score $<3$ subgroup, only two patients had died at 30 days $(5.9 \%)$. Appropriate antibiotic therapy rate was not significantly different between the Charlson score $<3$ subgroup and the Charlson score $\geq 3$ subgroup $(61.3 \%$ vs $57.1 \%, p=0.82)$.

Introduction of an interaction term between each covariate of multivariate logistic models did not reveal a significant association. 


\section{Discussion}

This study describes the characteristics of bacteremia related to all MDR bacteria types in a French university hospital center.

The patients included in this study had severe clinical condition with multiple comorbidities such as malignancy $(53.1 \%)$, diabetes $(31.1 \%)$, and chronic renal failure $(28.9 \%)$, as shown by the high Charlson comorbidity score: $70.2 \%$ of patients had a Charlson score $\geq 5$. The population's comorbidity profile seems similar to other comparable studies on bacteremias

due to MDR bacteria ${ }^{16-24}$, despite the heterogeneous types of MDR bacteria observed here. Majority of bacteremias have nosocomial acquisition (61.0\%). More than $80 \%$ of bacteremias are related to patients frequenting the care environment (nosocomial and healthcareassociated bacteremia).

Another important point brought out by this study concerns the colonization of patients by MDR bacteria before bacteremia. The proportion of patients with positive bacteriological samples in the preceding 2 months appeared high (18.9\%). However $20.9 \%$ of those patients with available MDR data received an inappropriate initial antibiotic therapy, which is comparable to the results of a recent study on ESBL bacteremias $(23 \%)^{16}$ but was twice as low as in the overall patient group. Nevertheless, this also suggests that the bacteriological antecedents had not been consulted systematically or that possible involvement of the previously known MDR bacterium was erroneously excluded when starting probabilistic antibiotic therapy. We can conclude that the appropriateness of initial antibiotic treatment can be optimized in case of bacteremia by taking more into account recent bacteriological history of colonization or infection by MDR bacteria in the prior 2 months. 
The mortality rate observed here is high, reflecting the severity of the symptoms. High levels are also found in the literature, regardless of the MDR bacteria etiology involved ${ }^{3,4,6,7}$. The inappropriate initial antibiotic therapy exceeding $41 \%$ also seems high in this study. Other studies have shown varied results such as $63 \%$ for Frakking et al. ${ }^{16}, 52.8 \%$ for Kang et al. $^{18}, 62.2 \%$ for Morata et al. ${ }^{20}$, and $67.1 \%$ for Paul et al. ${ }^{21}$. All of these results are high but the heterogeneity of the settings and etiologies precludes direct comparison.

We can observe that the appropriate initial antibiotic therapy rate differed according to the source of bacterial infection. In fact, initial antibiotic treatments are judged appropriate in case of urinary tract infection (66\%) more often than infections of unknown origin (35\%), for example. The appropriateness of the initial antibiotic treatment is influenced by the bacteriological probability, which depends on the source of infection, as has been suggested in other studies ${ }^{24,25}$. In multivariate analysis of risk factors associated with inappropriate antibiotic therapy, the presence of severe sepsis or septic shock appeared as a protective factor. This can be explained by the systematic use of combination therapy usually involving an aminoglycoside with beta-lactam in this clinical situation. This has the effect of extending the spectrum of activity of the treatment like that has been objectified.

However, this study has several limitations, the first of which is its retrospective design. In addition, the results observed cannot be generalizable because of the monocentric design, characteristic of referral centers and a lack of homogeneity in bacteremia etiologies. It should also be noted that the classification of bacterial species resistance is not uniform in all the studies published to date, especially in cases of $P$. aeruginosa $a^{4,20}$ and $A$. baumannii ${ }^{19}$. Indeed, the definition of MDR of these two bacteria was based on the definition used for the French national prevalence survey ${ }^{2}$. 
Moreover, possible misclassification error between appropriate and inappropriate antibiotic therapy is possible. In fact, in bacteremias due to ESBL producing bacteria, recent studies have demonstrated the absence of all-cause mortality difference between the carbapenems group and beta-lactam/beta-lactamase inhibitor combination group ${ }^{26}$. This suggests that bacteremias due to ESBL producing bacteria can be effectively treated with the betalactam/beta-lactamase inhibitor combination despite their severity. The pertinence of antibiotic therapy did not take into account the criterion of favorable clinical or bacteriological outcome, or the criterion of sufficient length of prescription of adequate treatment. In addition, the observation of antibiotic treatment at $72 \mathrm{~h}$ should have been added to analyze its appropriateness according to final results of bacterial identification and antibiotic susceptibility testing. Possible prior exposure to antimicrobial therapy was not sought, and minimum inhibitory concentrations of MDR bacterial strains were not analyzed in this study. Finally, the prevalence of bacteremia related to MDR bacteria could not be calculated.

To conclude, this study provides a comprehensive picture of all-cause bacteremia due to multidrug-resistant strains combined for this hospital. The key findings are a high rate of 30day mortality (23\%) and a high rate of inappropriate antibiotic treatment 1 day after a positive blood sample $(41.7 \%)$ even in patients with bacteriological antecedents to the same MDR bacteria in the prior two months (20.9\%). Thus, taking more into account antecedents of MDR bacteria could improve the rate of appropriate initial antibiotic therapy. 
Acknowledgments

Financial support. This study received no financial support.

Potential conflicts of interest. The authors have no conflicts of interest to declare in relation to this study. 
1. European Centre for Disease Prevention and Control. Antimicrobial resistance surveillance in Europe 2012. Annual Report of the European Antimicrobial Resistance Surveillance Network (EARS-Net). European Centre for Disease Prevention and Control. 2013. Stockholm, Sweden.

2. Réseau d'alerte, d'investigation et de surveillance des infections nosocomiales (Raisin). Enquête nationale de prévalence des infections nosocomiales et des traitements anti-infectieux en établissements de santé, France, mai-juin 2012. Résultats. Saint-Maurice : Institut de veille sanitaire. 2013.

3. Cosgrove SE, Sakoulas G, Perencevich EN, Schwaber MJ, Karchmer AW, Carmeli Y. Comparison of Mortality Associated with Methicillin-Resistant and MethicillinSusceptible Staphylococcus aureus Bacteremia: A Meta-analysis. Clin Infect Dis. 2003;36(1):53-59.

4. Tam VH, Rogers CA, Chang KT, Weston JS, Caeiro JP, Garey KW. Impact of Multidrug-Resistant Pseudomonas aeruginosa Bacteremia on Patient Outcomes. Antimicrob Agents Chemother. 2010;54(9):3717-3722.

5. Rottier WC, Ammerlaan HSM, Bonten MJM. Effects of confounders and intermediates on the association of bacteraemia caused by extended-spectrum $\beta$ lactamase-producing Enterobacteriaceae and patient outcome: a meta-analysis. $J$ Antimicrob Chemother. 2012;67(6):1311-1320.

6. Schwaber MJ, Carmeli Y. Mortality and delay in effective therapy associated with extended-spectrum $\beta$-lactamase production in Enterobacteriaceae bacteraemia: a systematic review and meta-analysis. J Antimicrob Chemother. 2007;60(5):913-920. 
7. Salgado CD, Farr BM. Outcomes Associated With Vancomycin-Resistant Enterococci: A Meta-Analysis. Infection Control and Hospital Epidemiology. 2003;24(9):690-698.

8. Cosgrove SE. The Relationship between Antimicrobial Resistance and Patient Outcomes: Mortality, Length of Hospital Stay, and Health Care Costs. Clinical Infectious Diseases. 2006;42(Supplement 2):S82-S89.

9. Charlson ME, Pompei P, Ales KL, MacKenzie CR. A new method of classifying prognostic comorbidity in longitudinal studies: Development and validation. Journal of Chronic Diseases. 1987;40(5):373-383.

10. Le Gall JR, Lemeshow S, Saulnier F. A new Simplified Acute Physiology Score (SAPS II) based on a European/North American multicenter study. JAMA. 1993;270(24):2957-2963.

11. Comité de l'antibiogramme de la société Française de microbiologie. Recommandations. 2011, 2012, 2013.

12. Comité technique des infections nosocomiales et des infections liées aux soins. Définition des infections associées aux soins. Ministère de la santé, de la jeunesse et des sports. 2007.

13. Conférence de consensus commune Sfar-SRLF : prise en charge hémodynamique du sepsis grave (nouveau-né exclus). Réanimation. 2006;15(5):418-419.

14. Leibovici L, Paul M, Poznanski O, et al. Monotherapy versus beta-lactamaminoglycoside combination treatment for gram-negative bacteremia: a prospective, observational study. Antimicrob Agents Chemother. 1997;41(5):1127-1133.

15. R Core Team. R: A language and environment for statistical computing. $\mathrm{R}$ Foundation for Statistical Computing, Vienna, Austria. 2013. 
16. Frakking FNJ, Rottier WC, Dorigo-Zetsma JW, et al. Appropriateness of empirical treatment and outcome in bacteremia caused by extended-spectrum- $\beta$-lactamaseproducing bacteria. Antimicrob Agents Chemother. 2013;57(7):3092-3099.

17. Kang CI, Kim SH, Park WB, et al. Bloodstream Infections Due to ExtendedSpectrum $\beta$-Lactamase-Producing Escherichia coli and Klebsiella pneumoniae: Risk Factors for Mortality and Treatment Outcome, with Special Emphasis on Antimicrobial Therapy. Antimicrob Agents Chemother. 2004;48(12):4574-4581.

18. Kang CI, Kim SH, Park WB, et al. Bloodstream Infections Caused by AntibioticResistant Gram-Negative Bacilli: Risk Factors for Mortality and Impact of Inappropriate Initial Antimicrobial Therapy on Outcome. Antimicrob Agents Chemother. 2005;49(2):760-766.

19. Lee NY, Lee HC, Ko NY, et al. Clinical and Economic Impact of Multidrug Resistance in Nosocomial Acinetobacter baumannii Bacteremia. Infection Control and Hospital Epidemiology. 2007;28(6):713-719.

20. Morata L, Cobos-Trigueros N, Martínez JA, et al. Influence of Multidrug Resistance and Appropriate Empirical Therapy on the 30-Day Mortality Rate of Pseudomonas aeruginosa Bacteremia. Antimicrob Agents Chemother. 2012;56(9):4833-4837.

21. Paul M, Kariv G, Goldberg E, et al. Importance of appropriate empirical antibiotic therapy for methicillin-resistant Staphylococcus aureus bacteraemia. J Antimicrob Chemother. 2010;65:2658-2665.

22. Shurland S, Zhan M, Bradham D, Roghmann MC. Comparison of Mortality Risk Associated With Bacteremia Due to Methicillin-Resistant and Methicillin-Susceptible Staphylococcus aureus. Infection Control and Hospital Epidemiology. 2007;28(3):273-279. 
23. Tumbarello M, Sanguinetti M, Montuori E, et al. Predictors of Mortality in Patients with Bloodstream Infections Caused by Extended-Spectrum- $\beta$-LactamaseProducing Enterobacteriaceae: Importance of Inadequate Initial Antimicrobial Treatment. Antimicrob Agents Chemother. 2007;51(6):1987-1994.

24. Tumbarello M, Sali M, Trecarichi EM, et al. Bloodstream Infections Caused by Extended-Spectrum- $\beta$-Lactamase- Producing Escherichia coli: Risk Factors for Inadequate Initial Antimicrobial Therapy. Antimicrob Agents Chemother. 2008;52(9):3244-3252.

25. Zaragoza R, Artero A, Camarena JJ, Sancho S, González R, Nogueira JM. The influence of inadequate empirical antimicrobial treatment on patients with bloodstream infections in an intensive care unit. Clinical Microbiology and Infection. 2003;9(5):412-418.

26. Vardakas KZ, Tansarli GS, Rafailidis PI, Falagas ME. Carbapenems versus alternative antibiotics for the treatment of bacteraemia due to Enterobacteriaceae producing extended-spectrum $\beta$-lactamases: a systematic review and meta-analysis. J Antimicrob Chemother. 2012; 67:2793-2803. 
Table 1. Characteristics of patients with bacteremia.

\begin{tabular}{|c|c|c|c|c|}
\hline \multirow[t]{2}{*}{ Variable } & \multirow{2}{*}{$\begin{array}{l}\text { All patients } \\
\boldsymbol{n}=228(\%)\end{array}$} & \multicolumn{2}{|c|}{ Patients at 30 days } & \multirow[t]{2}{*}{$P$-value } \\
\hline & & $\begin{array}{l}\text { Alive } \\
n=171(77 \%)\end{array}$ & $\begin{array}{l}\text { Dead } \\
n=51(23 \%)\end{array}$ & \\
\hline Age & & & & 0.004 \\
\hline $0-14$ & $7(3.0)$ & $6(3.5)$ & $1(2.0)$ & \\
\hline $15-64$ & $82(36.0)$ & $72(42.1)$ & $9(17.6)$ & \\
\hline$\geq 65$ & $139(61.0)$ & $93(54.4)$ & $41(80.4)$ & \\
\hline Male & $143(62.7)$ & $108(63.2)$ & $33(64.7)$ & 0.84 \\
\hline Obesity $(\boldsymbol{n}=214)$ & $35(16.4)$ & $30(18.5)$ & $5(10.9)$ & 0.22 \\
\hline \multicolumn{5}{|l|}{ Comorbidity } \\
\hline Solid tumor & $89(39.0)$ & $59(34.5)$ & $25(49.0)$ & 0.06 \\
\hline Hematologic tumor & $33(14.5)$ & $25(14.6)$ & $7(13.7)$ & 0.87 \\
\hline Diabetes & $71(31.1)$ & $53(31.0)$ & $15(29.4)$ & 0.83 \\
\hline Chronic respiratory & $34(14.9)$ & $24(14.0)$ & $9(17.6)$ & 0.52 \\
\hline \multicolumn{5}{|l|}{ failure/COPD ${ }^{\mathrm{a}}$} \\
\hline Chronic renal failure & $66(28.9)$ & $48(28.1)$ & $16(31.4)$ & 0.65 \\
\hline Chronic dialysis & $16(7.0)$ & $15(8.8)$ & $1(2.0)$ & 0.13 \\
\hline Liver disease & $29(12.7)$ & $16(9.4)$ & $12(23.5)$ & 0.007 \\
\hline Charlson comorbidity score & & & & 0.004 \\
\hline$\leq 2$ & $33(14.5)$ & $31(18.1)$ & $2(3.9)$ & \\
\hline $3-4$ & $35(15.3)$ & $30(17.6)$ & $4(7.9)$ & \\
\hline$\geq 5$ & $160(70.2)$ & $110(64.3)$ & $45(88.2)$ & \\
\hline Immunosuppression & & & & \\
\hline
\end{tabular}




\begin{tabular}{|c|c|c|c|c|}
\hline Immunosuppressive & $39(17.1)$ & $34(19.9)$ & $5(9.8)$ & 0.10 \\
\hline \multicolumn{5}{|l|}{ treatment } \\
\hline Corticosteroid treatment & $21(9.2)$ & $16(9.4)$ & $5(9.8)$ & 1.00 \\
\hline Chemotherapy & $37(16.2)$ & $30(17.5)$ & $7(13.7)$ & 0.52 \\
\hline Radiotherapy & $3(1.3)$ & $2(1.2)$ & $1(2.0)$ & 0.54 \\
\hline HIV & $2(0.9)$ & $2(1.2)$ & $0(0.0)$ & 1.00 \\
\hline Other immunosuppression & $6(2.6)$ & $3(1.8)$ & $3(5.9)$ & 0.14 \\
\hline Colonization $^{\mathrm{b}}(\boldsymbol{n}=98)$ & 43 (43.9) & $35(46.1)$ & $8(38.1)$ & 0.52 \\
\hline Invasive procedure in last 30 & $94(42.0)$ & $68(40.2)$ & $24(49.0)$ & 0.28 \\
\hline $\operatorname{days}^{c}(n=224)$ & & & & \\
\hline
\end{tabular}

a. Chronic obstructive pulmonary disease; b. colonization or bacteriological sample positive by the same MDR bacterium documented within 2 months prior to the bacteremic episode; c. surgical procedure or nonsurgical procedure performed in technical platform. 
Table 2. Characteristics of bacteremias due to multidrug resistant bacteria.

\begin{tabular}{|c|c|c|c|c|}
\hline \multirow[t]{2}{*}{ Variable } & \multirow{2}{*}{$\begin{array}{l}\text { All bacteremias } \\
\boldsymbol{n}=228(\%)\end{array}$} & \multicolumn{2}{|c|}{ Patients at 30 days } & \multirow[t]{2}{*}{$P$-value } \\
\hline & & $\begin{array}{l}\text { Alive } \\
n=171(77 \%)\end{array}$ & $\begin{array}{l}\text { Dead } \\
n=51(23 \%)\end{array}$ & \\
\hline Acquisition & & & & 0.32 \\
\hline Community onset & $45(19.7)$ & $33(19.3)$ & $10(19.6)$ & \\
\hline Healthcare-associated & $44(19.3)$ & $36(21.1)$ & $6(11.8)$ & \\
\hline \multirow[t]{2}{*}{ Nosocomial } & $139(61.0)$ & $102(59.6)$ & $35(68.6)$ & \\
\hline & & & & 0.06 \\
\hline Medical unit & $71(51.1)$ & $53(52.0)$ & $17(48.6)$ & \\
\hline Surgical unit & $33(23.7)$ & $29(28.4)$ & $4(11.4)$ & \\
\hline ICU & $18(12.9)$ & $10(9.8)$ & $7(20.0)$ & \\
\hline Postacute care and & $13(9.4)$ & $7(6.9)$ & $6(17.1)$ & \\
\hline \multicolumn{5}{|l|}{ rehabilitation unit } \\
\hline Long-term care unit & $4(2.9)$ & $3(2.9)$ & $1(2.9)$ & \\
\hline Bacteremia source & & & & 0.88 \\
\hline Vascular catheter infection & $18(7.9)$ & $14(8.2)$ & $4(7.8)$ & \\
\hline Urinary tract infection & $64(28.1)$ & $49(28.7)$ & $12(23.5)$ & \\
\hline Pulmonary infection & $14(6.1)$ & $9(5.3)$ & $5(9.8)$ & \\
\hline Surgical site infection & $18(7.9)$ & $15(8.8)$ & $3(5.9)$ & \\
\hline Intra-abdominal infection & $50(21.9)$ & $37(21.6)$ & $13(25.5)$ & \\
\hline Other infection & $24(10.5)$ & $18(10.5)$ & $5(9.8)$ & \\
\hline Unknown source or primary & $40(17.6)$ & $29(16.9)$ & $9(17.7)$ & \\
\hline bacteremia & & & & \\
\hline Related to a nonsurgical procedure & $13(39.4)$ & $10(43.5)$ & $3(37.5)$ & 1.00 \\
\hline
\end{tabular}


$(\mathbf{n}=33)$

Infection previously known ${ }^{\mathbf{a}}$

$25(11.0)$

$18(10.6)$

$7(13.7)$

0.54

$(\mathbf{n}=227)$

Bacteria species and resistance

mechanisms

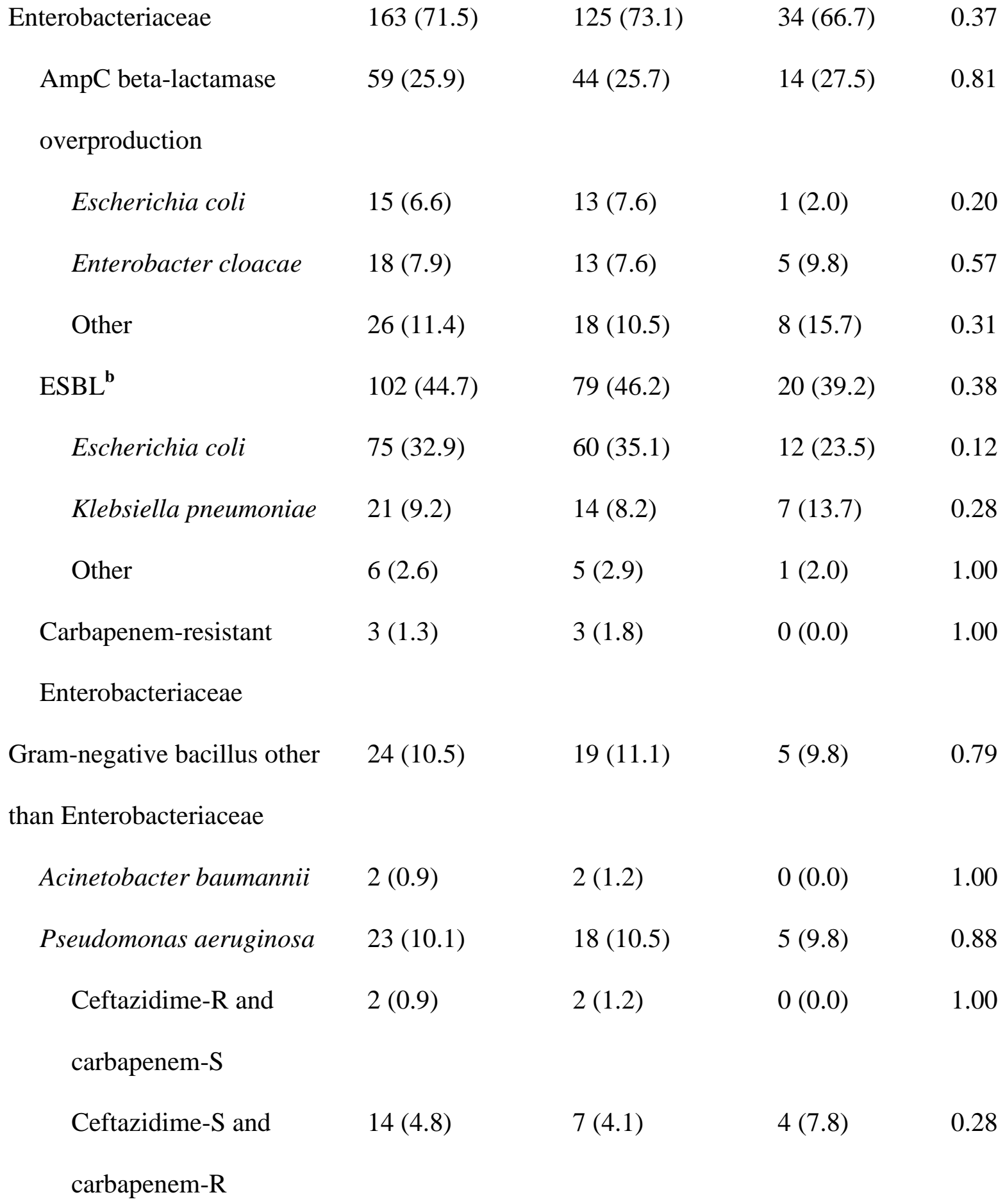




\begin{tabular}{|c|c|c|c|c|}
\hline $\begin{array}{l}\text { Ceftazidime-R and } \\
\text { carbapenem-R }\end{array}$ & $10(4.4)$ & $9(5.3)$ & $1(2.0)$ & 0.46 \\
\hline Gram-positive bacteria & $42(18.4)$ & $28(16.4)$ & $12(23.5)$ & 0.24 \\
\hline $\mathrm{MRSA}^{\mathrm{c}}$ & $40(17.5)$ & $27(15.8)$ & $11(21.6)$ & 0.34 \\
\hline $\mathrm{VRE}^{\mathbf{d}}$ & $2(0.9)$ & $1(0.6)$ & $1(2.0)$ & 0.41 \\
\hline$\geq 2$ bacteria & $41(18.0)$ & $26(15.2)$ & $15(29.4)$ & 0.02 \\
\hline $\begin{array}{l}\text { Severe sepsis or septic shock } \\
(\boldsymbol{n}=222)\end{array}$ & $68(30.6)$ & $36(21.6)$ & $32(65.3)$ & $<0.001$ \\
\hline Median length of stay (IQR) before & $13(6-31.5)$ & $13(6-31,25)$ & $10(5.5-$ & 0.46 \\
\hline bacteremia $(\text { days })^{\mathbf{e}}(\boldsymbol{n}=139)$ & & & $31,5)$ & \\
\hline Recurred within 90 days & $15(6.6)$ & $12(7.0)$ & $3(5.9)$ & 1.00 \\
\hline Inappropriate antibiotic therapy at & $91(41.7)$ & $69(41.8)$ & $21(43.8)$ & 0.81 \\
\hline 1 day $(n=218)$ & & & & \\
\hline
\end{tabular}

a. Documented infection with the same MDR bacterium before bacteremia onset; $b$. extendedspectrum- $\beta$-lactamase; c. methicillin-resistant Staphylococcus aureus; d. vancomycinresistant Enterococcus; e. time from admission to bacteremia onset for nosocomial acquisition bacteremia. 
Table 3. Analysis of risk factors associated with 30-day mortality in adult population.

\begin{tabular}{|c|c|c|c|c|}
\hline \multirow[t]{2}{*}{ Variable } & \multicolumn{2}{|l|}{ Univariate analysis } & \multicolumn{2}{|c|}{ Multivariate analysis of final model } \\
\hline & OR $(95 \% \mathrm{CI})$ & $P$-value & Adjusted OR (95\% CI) & $P$-value \\
\hline Male & $1.01(0.51-2.00)$ & 0.98 & & \\
\hline Age $\geq 65$ years & $3.44(1.51-7.87)$ & $<0.01$ & $6.08(2.17-17.04)$ & $<0.001$ \\
\hline Charlson comorbidity score $\geq 3$ & $4.18(0.99-17.56)$ & 0.02 & & \\
\hline Malignancy & $1.68(0.86-3.30)$ & 0.13 & $2.24(0.99-5.07)$ & 0.053 \\
\hline Liver disease & $3.44(1.47-8.04)$ & $<0.01$ & $6.56(2.15-19.97)$ & $<0.001$ \\
\hline Immunosuppression & $0.85(0.42-1.72)$ & 0.66 & & \\
\hline Healthcare-associated & $0.93(0.42-2.07)$ & 0.86 & & \\
\hline \multicolumn{5}{|l|}{ infection } \\
\hline ICU acquisition & $2.46(0.66-9.11)$ & 0.18 & & \\
\hline Urinary tract infection source & $0.67(0.31-1.46)$ & 0.31 & & \\
\hline Severe sepsis or septic shock & $6.81(3.31-14.01)$ & $<0.001$ & $8.96(3.86-20.80)$ & $<0.001$ \\
\hline Inappropriate initial antibiotic & $0.98(0.50-1.92)$ & 0.96 & & \\
\hline \multicolumn{5}{|l|}{ therapy } \\
\hline Bacteremia $\geq 2$ bacteria & $2.64(1.24-5.61)$ & 0.01 & $3.62(1.42-9.27)$ & 0.007 \\
\hline $\mathrm{ESBL}^{\mathrm{a}}$ & $0.70(0.35-1.38)$ & 0.30 & & \\
\hline AmpC beta-lactamase & $1.28(0.62-2.64)$ & 0.51 & & \\
\hline \multicolumn{5}{|l|}{ overproduction } \\
\hline P. aeruginosa $\mathrm{CAZ}-\mathrm{R}$ and/or & $0.86(0.27-2.71)$ & 0.80 & & \\
\hline carbapenem- $\mathrm{R}^{\mathbf{b}}$ & & & & \\
\hline
\end{tabular}




\begin{tabular}{lcc}
\hline MRSA $^{\mathbf{c}}$ & $1.39(0.59-3.24)$ & 0.45 \\
Infection previously known $^{\mathbf{d}}$ & $1.03(0.36-2.96)$ & 0.96 \\
Length of stay before & $1.27(0.59-2.71)$ & 0.54 \\
bacteremia $\geq 21$ days & & \\
\hline
\end{tabular}

a. Extended-spectrum- $\beta$-lactamase; b. ceftazidime-resistant or carbapenem-resistant; $c$. methicillin-resistant Staphylococcus aureus; d. documented infection to the same MDR bacterium before bacteremia onset. 